The main reason for discrepancy between the two methods of evaluation thus seems to be a difference of threshold.

\section{Summary}

Sixty-five episodes of complete clinical remission in 46 patients with a verified diagnosis of non-specific haemorrhagic proctocolitis were studied with respect to macroscopic and microscopical signs of mucosal inflammation.

The microscopical evaluation was based on the cytological method described in a previous paper. Macroscopic assessment was made by sigmoidoscopy with the use of conventional criteria.

In 31 episodes sigmoidoscopy revealed macroscopically abnormal mucosas; in 24 of these the cytological preparations also showed inflammatory changes, while the cytological pictures were normal in seven. In the remaining 34 episodes no mucosal changes were found at sigmoidoscopy ; in 16 of these distinct inflammation was seen microscopically, while normal cytology was demonstrated in 18 .

In about two-thirds of the episodes of patients with remissions shorter than six months the cytological method showed inflammatory changes, whereas the corresponding proportion in remissions of more than six months' duration was only slightly over two-fifths.
The ability of microscopical techniques-like the cytological method used in the present investigation-to demonstrate unequivocal signs of inflammation in proctocolitis patients who are in full clinical remission, and who may even show a normal sigmoidoscopical picture, can be utilized diagnostically when such patients are first seen in a symptom-free or symptom-poor phase. The fact also points to the latent chronicity of nonspecific haemorrhagic proctocolitis and calls for circumspection with regard to the prognosis of the disease.

\section{REFERENCE}

Anthonisen, P., Hvidberg, E., and Riis, P. (1963). Ugeskr. Laeg., 125, 501.

— and Riis, P. (1961). Lancet, 2, 81.

- (1962). Acta med. scand., 172, 375.

Baron, J. H., Connell, A. M., and Lennard-Jones, J. E. (1964). Brit. med. 7., $1,89$.

Dick, A. P., and Grayson. M. J. (1961). Ibid., 1, 160.

Flick, A. L., Voegtlin, K. F., and Rubin, C. E. (1962). Gastroenterology, 42, 69i.

Kinsey, I., Hornnes, N., Anthonisen, P., and Riis, P. (1964). Acta med. scand., 176, 181.

Lumb, G., and Protheroe, R. H. B. (1955). Lancet, 2, 1208.

Matts, S. G. F. (1961). Quart F. Med., 30, 393.

Riis, P., and Anthonisen, P. (1964). Acta med. scand., 175, 85.

Truelove, S. C., Horler, A. R., and Richards, W. C. D. (1955). Brit. med. F., 2, 1590 .

- and Richards, W. C. D. (1956). Ibid., 1, 1315.

\title{
Functional and Structural Studies of Small Bowel in Ankylostomiasis
}

\author{
B. N. TANDON,* M.D. ; B. C. DAS $\dagger$ M.B., B.S. ; A. K. SARAYA, $\ddagger$ M.D. ; M. G. DEO,§ M.D.
}

Brit. med. F., 1966, 1, 714-716

Ankylostomiasis is a widely prevalent problem of tropical countries. Several aspects of this malady remain to be investigated (W.H.O., 1959), and one of these pertains to the functional and structural changes of the small bowel. In the early part of this century Ashford and King (1907) and Whipple (1909) independently reported intestinal damage in necropsy studies of hookworm-infested subjects. This was later supported by Rotter (1931), who, from post-mortem studies, gave a detailed description of histological changes of the small gut in ankylostomiasis. In recent years the availability of a simple peroral intestinal biopsy capsule gave a fresh impetus to the study of intestinal disorders. During the past five years conflicting reports on intestinal reaction in patients with ankylostomiasis have appeared in the literature. While some investigators (Sheehy et al., 1962, Salem and Truelove, 1964 ; Chaudhuri and Saha, 1964) have recorded definite and significant evidence of intestinal damage in this condition, others have failed to do so (Gilles et al., 1964 ; Layrisse et al., 1964). The present study was therefore undertaken to obtain information about intestinal structure and function in subjects with ankylostomiasis infestation.

\section{Selection of Cases and Methods}

Twenty-two adult males, whose stools were positive for hookworm ova and who had no other associated disease, formed the subjects for this study. Their ages ranged from 18 to 25 years. Nineteen non-infected healthy adult males were studied as controls. Their ages ranged from 20 to 35 years. Both these groups belonged to the lower socio-economic strata of the rural population. In addition to clinical examination each patient had his haemoglobin concentration determined and blood smear examined by standard methods (Dacie, 1956; A.F.I.P. Laboratory, 1924). In all cases bone-marrow studies were carried out and a fat-balance test was done on a diet containing $100 \mathrm{~g}$. of fat. After an initial period of stabilization over five days the faeces were collected for 48 hours for analysis of fat by the method of Van de Kamer et al. (1949). A 5-g. D-xylose-absorption test was done according to the method of Roe and Rice (1948). A jejunal biopsy specimen was taken by Rubin's multipurpose capsule $5-10 \mathrm{~cm}$. distal to the ligament of Treitz. The dietary history of the patients was recorded according to the Indian standards worked out by the Indian Council of Medical Research (I.C.M.R., 1963).

\section{Results}

The clinical observations are recorded in the Table. It was noted that about one-third of the patients had frequent loose stools, though none of them gave a characteristic description suggestive of steatorrhoea. Pitting oedema of the lower extremities was observed in three of the patients.

* Assistant Professor, Department of Medicine, All India Institute of Medical Sciences, New Delhi.

† Postgraduate Student, Department of Medicine, All India Institute of Medical Sciences, New Delhi.

₹ Assistant Professor, Department of Pathology, All India Institate of Medical Sciences, New Delhi.

$\checkmark$ Assistant Professor, Department of Pathology. All India Institute of Medical Sciences, New Delh: 
All the control subjects had haemoglobin levels above $12 \mathrm{~g} . /$ $100 \mathrm{ml}$. If a level below $12 \mathrm{~g}$. is accepted as an indication of anaemia, all but two patients were anaemic. Of the anaemic group seven had haemoglobin levels below $5 \mathrm{~g} ., 11$ in the range of 5.1 to $9 \mathrm{~g}$., and the remaining two had levels of $10 \mathrm{~g}$. and 10.5 g. respectively. Peripheral blood smears in anaemic patients showed severe hypochromia, microcytosis, anisocytosis, poikilocytosis, and the presence of a few target cells with an increase of eosinophils. The marrow showed an erythroid hyperplasia with a reversal of the myeloid-erythroid ratio and normoblasts in all stages of maturation, showing poor haemoglobinization. There was a preponderance of eosinophilic myelocytes, with an increase in plasma cells in a few cases. Pearl's reaction for free iron showed absence of haemosiderin in all the patients. D-xylose and fat-absorption in 19 healthy individuals were noted to be $1.7 \pm 0.47 \mathrm{~g}$. and $2.5 \pm 1.61 \mathrm{~g}$. respectively. An increased excretion of faecal fat of more than 5 g. $/ 24$ hours was recorded in nine cases. Urinary $D$-xylose excretion of less than $1 \mathrm{~g}$. in five hours was recorded in three patients.

Salient Clinical Features of 22 Patients with Ankylostomiasis

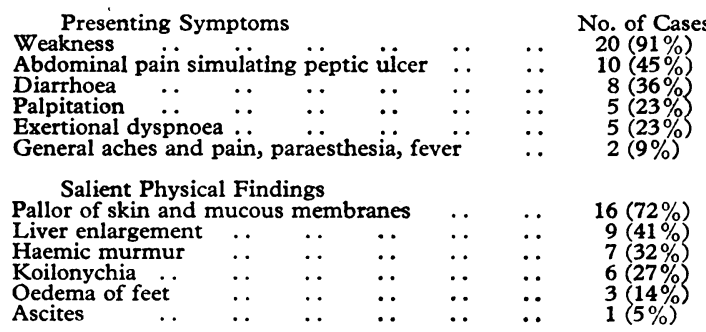

Jejunal biopsy studies in controls revealed a normal histology in 18 cases, and one subject had mild blunting and fusion of the villi. Eleven out of 22 patients had normal histology of the jejunal mucosa (Fig. 1). Four patients had only mild abnormalities, characterized by increased cellular infiltration in the lamina propria and focal fusion and blunting of the villi. "Partial villous atrophy" (Fig. 2)-characterized by a mild reduction of the villous crypt ratio, a varying degree of fusion and blunting of the villi, and an increased degree of cellular infiltration of the lamina propria-was observed in three patients. The remaining four had "subtotal villous atrophy," with a marked reduction of villous crypt ratio, fusion and blunting of the villi, increase in the depth of the crypts, loss of polarity and atypicality of the villous epithelial cells, and cellular infiltration of the lamina propria (Fig. 3). The cellular infiltration in all the abnormal biopsy specimens was predominantly composed of lymphocytes and plasma cells. The eosinophilic infiltration was not different from that observed in the jejunal biopsy specimens of healthy controls. The dietary history of patients showing structural changes of the jejunal mucosa revealed a mean total intake of 2,200 calories with a protein content of $70 \mathrm{~g}$. A correspondingly mean intake of 2,500 calories with a protein content of $73 \mathrm{~g}$. was recorded in cases of hookworm infestation with normal mucosal histology.

\section{Discussion}

In their necropsy studies on cases of ankylostomiasis Ashford and King (1907), Whipple (1909), and Rotter (1931) have recorded histological changes characterized by oedema, scarring, atrophy, haemorrhage, and chronic inflammation of the mucosa and submucosa of the small intestine. The validity of these observations is, however, open to question, as the fallacies of histological studies of intestinal mucosa at necropsy, due to rapid autolysis, are quite well known. Recently, in small series of cases, Sheehy et al. (1962), Salem and Truelove (1964), and Chaudhuri and Saha (1964) reported histological abnormalities of the jejunal biopsy specimens in hookworm disease.
The results of the present study, based on a larger number of cases and compared with non-infested controls, support the findings of these earlier investigators. However, it was noted that in their series intestinal damage was found in all patients with hookworm disease, whereas in the present series only half of the cases studied had jejunal biopsy abnormalities. Of these, unequivocal abnormalities of partial or total villous atrophy were observed in seven cases, and four had only mild abnormalities similar to one observed in a control subject. Doubts

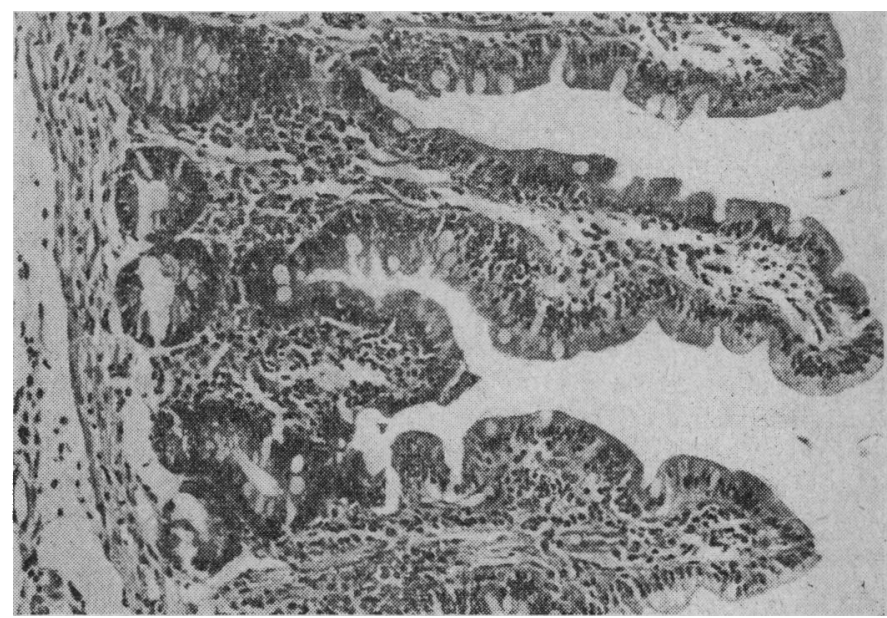

FIG. 1.-Jejunal biopsy from a case of ankylostomiasis presenting normal histological features. (H. and E. $\times 250$.)

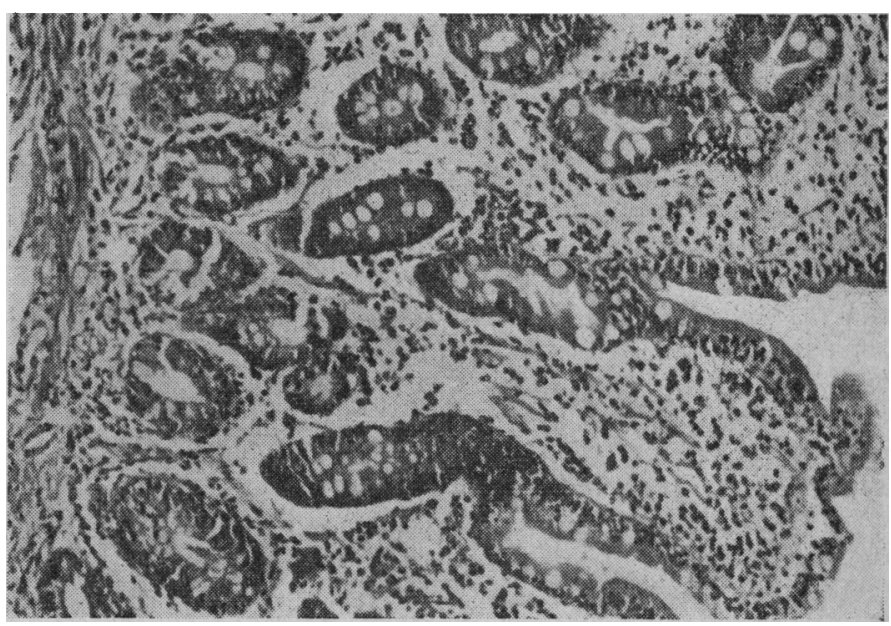

FIG. 2.-Partial villous atrophy (grade II change) in ankylostomiasis.

The villi are significantly shortened, blunted, and occasionally fused. (H. and E. $\times 250$.)

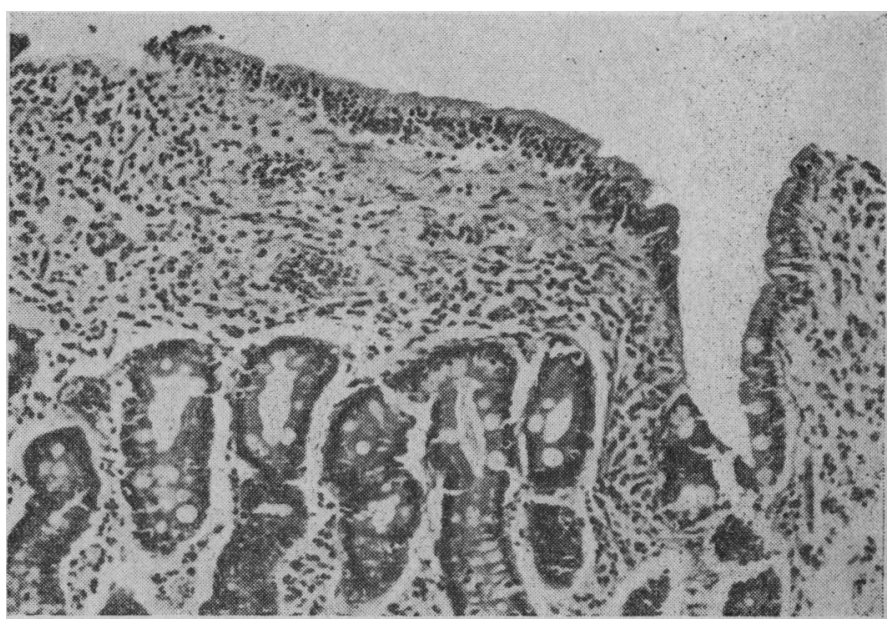

FIG. 3.- Subtotal villous atrophy (grade III change) in the jejunum. The villi are markedly blunted and fused over wide areas with dense infiltration of lamina propria. (H. and $\mathrm{E}$. $\times 250$.) 
have been expressed about the significance of minor histological changes of jejunal biopsy specimens (B.M.f., 1965). Further, It is of interest that one of the two cases with hookworm Infestation but without any clinical symptoms and anaemia showed evidence of advanced jejunal mucosal damage (subtotal villous atrophy, Fig. 3). This is contrary to the findings of Sheehy et al. (1962), who failed to record intestinal abnormalities in their "asymptomatic" patient with ankylostomiasis. These discrepancies can be explained on the basis of the inherent limitations of intestinal biopsy technique in regard to the sampling of the tissue affected by focal lesions.

Chaudhuri and Saha (1964) stressed the preponderance of eosinophilic infiltration of the lamina propria of the jejunal mucosa in patients with ankylostomiasis. We have failed to substantiate this observation.

The variations in the clinical picture of ankylostomiasis is well known, and while some patients present with evidence of advanced deficiency state, others remain quite healthy. Several factors may be responsible for this. As early as 1931 Rotter suggested that cachexia observed in patients with hookworm infestation could be due to impaired absorption of nutrients, as a consequence of the atrophy of the intestinal mucosa. This statement has support from the studies of Sheehy et al. (1962) and of Salem and Truelove (1964). In the present study defective absorption of fat was found in 9 out of 22 patients and D-xylose absorption was poor in only three patients. The patients with absorption defects showed general features of wasting, weakness, diarrhoea, and nutritional deficiency state. The abnormal absorption tests were associated with corresponding structural abnormality in all but three patients. It may therefore be suggested that intestinal alterations in patients with ankylostomiasis influence the clinical picture, and the long-term effects of such abnormalities require further study, with special reference to tropical sprue.

The pathogenesis of intestinal damage in ankylostomiasis is not clearly understood. Parasitism (Sheehy et al., 1962), associated anaemia, and malnutrition (Layrisse et al., 1964) may be involved. In the present study there was no direct correlation between the degree of anaemia and the severity of intestinal damage. Rawson and Rosenthal (1960) reported that irondeficiency anaemia in adults per se did not cause intestinal mucosal abnormalities. It was also noted in the present study that the nutritional status of half of the patients in whom a jejunal biopsy specimen showed evidence of structural abnor- mality was similar to that of the other half of the cases who had normal histology of the jejunum. This indirect evidence suggests that anaemia and nutritional factors may not play a decisive part in the pathogenesis of intestinal reaction in hookworm infestation. Obviously there is need for further elucidation of the specific role of the parasite and associated factors in the evolution of structural damage or functional impairment of the small intestine in patients with ankylostomiasis.

\section{Summary}

Intestinal changes in 22 patients with hookworm infestation were investigated by fat-balance and $\mathbf{D}$-xylose-absorption tests and intestinal biopsy studies. Jejunal biopsy specimens were abnormal in half of the cases. Increased faecal-fat excretion was present in nine cases and D-xylose absorption was poor in three. These findings indicate that intestinal damage, with associated features of malabsorption syndrome, may be frequently encountered in persons with hookworm infestation.

We are grateful to Dr. V. Ramalingaswami for his guidance in interpretation of the histology of the jejunal biopsy specimens. The help given by Miss S. Dua and Miss M. M. Ahuja, the dietitians, in recording the dietetic history is acknowledged with thanks.

\section{REPERENCES}

A.F.I.P. Laboratory (1924). In F. B. Mallory and J. H. Wright's Pathological Technique, 8th ed., p. 207. Saunders, Philadelphia.

Ashford, B. K., and King, W. W. (1907). F. Amer. med. Ass., 49, 471.

Brit. med. F., 1965, 1, 1331.

Chaudhuri, R. N., and Saha, T. K. (1964). Amer. F. trop. Med. Hyg.,

13, 410. (1956). Practical Haematology, 2nd ed., p. 31. Churchill, London.

Gilles, H. M., Watson Williams, E. J., and Ball, P. A. J. (1964). Quart. F. Med., 33, 1 .

I.C.M.R. (1963). Special Report Series No. 42.

Layrisse, M., Blumenfeld, N., Carbonell, L., Desenne, J., and Roche, M. (1964). Amer. F. trop. Med. Hyg., 13, 297.

Rawson, A., and Rosenthal, F. D. (1960). Lancet, 1, 730.

Roe, J. H., and Rise, E. W. (1948). Y. biol. Chem., 173, 507.

Rotter, W.' (1931). Virchows Arch. path. Anat., 280, 587.

Salem, S. N., and Truelove, S. C. (1964). Brit. med. I., 1, 1074

Sheehy, T. W., Meroney, W. H., Cox, R. S., jun., and Soler, J. E. (1962). Gastroenterology, 42, 148.

Van de Kamer, J. H., Bokkel-Huinink, H. T., and Weyers, H. A. (1949). f. biol. Chem., 177, 347 .

Whipple, G. H. (1909). Amer. 7. med. Sci., 138, 40.

World Health Organization (1959). Wld Hlth Org. techn. Rep. Ser., No. 182.

Brit. med. F., 1966, 1, 716-718

The pain associated with dysmenorrhoea or labour can be provoked by mechanical, chemical, or electrical stimuli applied to the cervix, particularly in the neighbourhood of the internal os uteri. Much of the sensory outflow of the uterus is concentrated in this area, and pain provoked in the cervix is indistinguishable from that provoked in the body of the uterus. The term "uterine pain" will therefore be used to describe pain provoked by an electrical stimulus passed through an electrode in the cervical canal. Pain so caused in a healthy woman usually begins in the midline of the abdomen about

* From the Obstetric Unit, University College Hospital, London.
$1 \frac{1}{2}$ in. $(3.8 \mathrm{~cm}$.) above the symphysis pubis. As the stimulus is increased the pain spreads across the lower abdomen, reaching to a line drawn across it just below the level of the anterior superior iliac spines. Pain may also be felt for a short distance down the insides of both thighs. This cutaneous area of reference is innervated by the ilio-hypogastric and ilio-inguinal nerves ( $\mathrm{T} \mathrm{12,} \mathrm{and} \mathrm{L} \mathrm{1,} \mathrm{and} \mathrm{2)} \mathrm{(Theobald,} \mathrm{1941,}$ 1949a, 1949b, 1955).

Uterine pain may be relieved either by infiltrating the parametric tissue with a local anaesthetic (Harttung, 1933; Sutherland, 1937), or by damaging the autonomic nerves in this tissue either with carbolic acid (Doppler, 1925) or with 